\title{
BMJ Open Effect of socio-demographic factors on the association between multimorbidity and healthcare costs: a population- based, retrospective cohort study
}

\author{
Kednapa Thavorn, ${ }^{1,2,3}$ Colleen J Maxwell,, ${ }^{3,4}$ Andrea Gruneir, ${ }^{3,5,6,7}$ \\ Susan E Bronskill, ${ }^{3,5}$ YuQing Bai, ${ }^{3}$ Anna J Koné Pefoyo, ${ }^{8,9}$ Yelena Petrosyan, ${ }^{1,5}$ \\ Walter P Wodchis ${ }^{3,5,10}$
}

To cite: Thavorn $\mathrm{K}$,

Maxwell CJ, Gruneir A, et al. Effect of socio-demographic factors on the association between multimorbidity and healthcare costs: a population-based, retrospective cohort study. BMJ Open 2017;7:e017264. doi:10.1136/ bmjopen-2017-017264

- Prepublication history and additional material for this paper are available online. To view, please visit the journal (http:// dx.doi.org/10.1136/bmjopen2017-017264).

Received 11 April 2017 Revised 3 August 2017 Accepted 11 August 2017

CrossMark

For numbered affiliations see end of article.

Correspondence to Dr Walter P Wodchis; walter.wodchis@utoronto.ca

\section{ABSTRACT}

Objectives To estimate the attributable costs of multimorbidity and assess whether the association between the level of multimorbidity and health system costs varies by socio-demographic factors in young $(<65$ years) and older ( $\geq 65$ years) adults living in Ontario, Canada.

Design A population-based, retrospective cohort study Setting The province of Ontario, Canada

Participants 6639089 Ontarians who were diagnosed with at least one of 16 selected medical conditions on 1 April 2009.

Main outcome measures From the perspective of the publicly funded healthcare system, total annual healthcare costs were derived from linked provincial health administrative databases using a person-level costing method. We used generalised linear models to examine the association between the level of multimorbidity and healthcare costs and the extent to which sociodemographic variables modified this association.

Results Attributable total costs of multimorbidity ranged from $\mathrm{C} \$ 377$ to $\mathrm{C} \$ 2073$ for young individuals and $\mathrm{C} \$ 1026$ to $\mathrm{C} \$ 3831$ for older adults. The association between the degree of multimorbidity and healthcare costs was significantly modified by age $(p<0.001)$, sex $(p<0.001)$ and neighbourhood income $(p<0.001)$ in both age groups, and the positive association between healthcare costs and levels of multimorbidity was statistically stronger for older than younger adults. For individuals aged 65 years or younger, the increase in healthcare costs was more gradual in women than in their male counterparts, however, for those aged 65 years or older, the increase in healthcare costs was significantly greater among women than men. Lastly, we also observed that the positive association between the level of multimorbidity and healthcare costs was significantly greater at higher levels of marginalisation.

Conclusion Socio-demographic factors are important effect modifiers of the relationship between multimorbidity and healthcare costs and should therefore be considered in any discussion of the implementation of healthcare policies and the organisation of healthcare services aimed at controlling healthcare costs associated with multimorbidity.
Strengths and limitations of this study

- This population-based study was based on a large sample size and used robust costing and generalised linear model regression techniques.

- The availability of linked and patient-level health administrative databases allows the estimation of the total health system costs associated with multimorbidity from all healthcare sectors.

- The use of health administrative databases can also minimise potential recall and non-response biases that are commonly found in survey data.

- The total healthcare costs reported in this study may be underestimated because they were derived based on 16 selected medical conditions. Moreover, it was not possible to measure certain costs (eg, deductibles and copayments borne by supplemental health insurance, out-of-pocket beneficiary payments and indirect costs associated with caregiving) with our data.

- The study did not take into account particular clusters of medical conditions. It is possible that the relationship between multimorbidity and healthcare costs may vary according to the types and patterns of comorbid medical conditions.

\section{BACKGROUND}

Multimorbidity, the presence of two or more coexisting conditions within a single person, is increasingly prevalent due to advances in life-extending medical treatments and increases in life expectancy. ${ }^{12}$ Internationally, the prevalence of multimorbidity has been shown to range from $17 \%$ in young adults ${ }^{3}$ to $82 \%$ in older adults living in nursing homes. ${ }^{4}$ In the province of Ontario, Canada, the prevalence of multimorbidity based on 16 selected conditions rose from $17.4 \%$ in 2003 to $24.3 \%$ in 2009 , and this increase was evident across all age groups. ${ }^{5}$

Higher levels of multimorbidity are associated with impaired physical functioning, ${ }^{6}$ 
poorer quality of life, ${ }^{7}$ more frequent use of health services and higher risk of death. ${ }^{8}$ In addition, individuals with multimorbidity may experience faster disease progression and require more complex medical care. ${ }^{9}$ Consequently, these individuals may be at a higher risk of receiving suboptimal care ${ }^{10}$ inappropriate prescriptions ${ }^{11}$ and experiencing potentially preventable hospitalisations. ${ }^{12}$ These adverse health outcomes can impose a substantial burden on patients, family caregivers and the healthcare system.

The relationship between multimorbidity and healthcare costs is well-documented and has been shown to be curvilinear or exponential across jurisdictions. The average Medicare payments in the USA ranged from US\$1154 among part A and part B beneficiaries with one chronic condition to US $\$ 13973$ among beneficiaries with at least four chronic conditions (a 12-fold difference). ${ }^{12}$ Similarly, the mean total health system costs among older adults with multimorbidity in Switzerland were nearly six times higher than among those without multimorbidity. ${ }^{13}$

Despite an abundance of research describing the relationship between multimorbidity and healthcare costs, existing studies have some important methodological and conceptual limitations. Some previous studies ${ }^{14} 15$ used ordinary least squares (OLS) regression despite the fact that the positively skewed distribution of cost data often violates the normality assumption of OLS. ${ }^{16}$ Others attempted to overcome this problem by transforming cost data to the logarithmic scale ${ }^{13}{ }^{17}$; however, this transformation may still result in interpretation problems, as regression on transformed costs provides the prediction of a median instead of the arithmetic mean costs. ${ }^{18}$ Importantly, the role of socio-demographic characteristics as effect modifiers of the relationship between multimorbidity and healthcare costs remains poorly described, although previous research has shown that the specific types of disease clusters vary by age and $\operatorname{sex}^{2} 19$ and that multimorbidity is more prominent in selected visible minority and low-socioeconomic status populations. ${ }^{20}$

The objectives of this study were, therefore, to estimate the health system costs attributable to multimorbidity using a more rigorous and appropriate approach, and to assess the extent to which the relationship between the level of multimorbidity and health system costs varies according to socio-demographic characteristics.

\section{METHODS}

\section{Study design and sample}

This population-based, retrospective cohort study included all residents of the province of Ontario between 1 April 2001 and 31 March 2010, who were enrolled in the Ontario Health Insurance Plan (OHIP), and were diagnosed with at least one of the following selected 16 medical conditions between 1 April 2001 and 31 March 2009 (study index date): acute myocardial infarction (AMI), arthritis, asthma, cancer, cardiac arrhythmia, chronic coronary syndrome, chronic obstructive pulmonary disorder (COPD), congestive heart failure, dementia, depression, diabetes, hypertension, osteoporosis, renal failure, rheumatoid arthritis and stroke. These conditions were selected because previous research and clinical experts agreed that they were highly prevalent and represented a substantial care and economic burden for Canada's healthcare system. ${ }^{521}$ We excluded individuals if they met the following criteria: had an invalid health card number, were older than 105 years, died or moved out of the province prior to the index date. Individuals with no contact with the healthcare system within the past 5 years prior to the index date were also excluded (excepting infants), as they may have left the province or experienced an unreported death.

\section{Data sources}

We linked multiple provincial health administrative databases anonymously using unique encrypted identifiers. The Discharge Abstract Database provides data for all hospital discharges in Ontario, and the OHIP claims database includes billing claims for all physician encounters. We used the Registered Persons Database to identify Ontarians who were eligible for health insurance coverage and derive their age. The linked database was housed and secured at the Institute for Clinical Evaluative Sciences (ICES) under data security and privacy policies and procedures approved by the Information and Privacy Commissioner of Ontario. This study was approved by the Research Ethics Board at Sunnybrook Health Sciences Centre, Toronto, Ontario, Canada.

Each medical condition was defined using diagnostic algorithms and consultation codes that have been validated or used in previous studies. We defined six conditions (AMI, asthma, chronic heart failure, COPD, diabetes and hypertension) based on validated population-derived registries held at ICES. ${ }^{22-28}$ These conditions were all defined based on one diagnosis recorded in acute care or two diagnoses recorded in ambulatory care (physician) records within a 2-year period (ie, between 2007/2008 and 2008/2009), except for AMI, which was defined using acute care records in 2008/2009. A similar approach was adopted to define the remaining medical conditions including arthritis, cancer, cardiac arrhythmia, chronic coronary syndrome, dementia, depression, osteoporosis, renal failure, rheumatoid arthritis and stroke. A list of diagnostic codes used to define these medical conditions are shown in online supplementary appendix 1 .

\section{Measures}

Healthcare costs

Healthcare costs were estimated from the perspective of the publicly funded healthcare system; accordingly, only direct costs borne to the Ontario Ministry of Health and Long-Term Care were considered. In Ontario, medically necessary hospital and physician services are paid for by the publicly financed health insurance plan; however, public coverage for prescription drugs is primarily limited to residents aged 65 years and over, social assistance 
recipients as well as those with high prescription drug costs compared with their net household income.

We identified, measured and valued direct healthcare costs by applying a person-level costing technique that was developed and validated based on the Ontario health administrative data. ${ }^{29}$ We calculated the costs of inpatient hospitalisations, emergency department visits, same day surgeries and inpatient rehabilitation by multiplying the weighted volume of services by the average provincial costs per weighted case. We obtained the costs of fee-for-service physician and outpatient diagnostic or laboratory services through OHIP fee approved as outlined in the Ontario Health Insurance Schedule of Benefits and Fees. ${ }^{30}$ Non-fee-for-service physician payments were calculated by applying applicable capitation payments or the median amount reimbursed for the same service code for the specific fiscal year. ${ }^{29}$ Costs for high-cost medical device equipment were estimated from the amount reimbursed to patients recorded in the Assistive Devices Program database. Complex continuing care and inpatient psychiatric costs were based on case mix, number of days in care and resource utilisation groups. ${ }^{31}$ Patient costs for long-term care were estimated based on a fixed per diem according to prevailing government payment rates, and costs for home care were estimated using the average cost per hour. We used pharmacy payments recorded in the Ontario Drug Benefit database to capture prescription medication costs for individuals eligible for public coverage. Annual total direct healthcare costs were the sum of costs across healthcare sectors for each patient for a 1-year period after the study index date, that is, from April 2009 to March 2010.

We categorised healthcare costs into five components: physician, hospital, drug, continuing care and other healthcare delivery costs. Physician costs included professional fees paid by the provincial insurance plan directly to physicians in private practice. Hospital costs included amounts paid to healthcare institutions, including those providing acute care, extended and chronic care, rehabilitation and convalescent care, psychiatric care as well as drugs dispensed in hospitals. Drug costs consisted of the costs of prescriptions dispensed at outpatient pharmacies to individuals eligible for provincial coverage while continuing care costs included expenditure on home care and residential long-term (nursing-home) care. The other healthcare delivery costs category represented expenditures on an assistive device programme that subsidises high-cost equipment, such as wheel chairs, walkers, continuous positive airway pressure devices and insulin pumps, for patients with physical disabilities. All costs were expressed in 2009 Canadian Dollars (C\$).

\section{Independent variables}

Multimorbidity was defined as the occurrence of two or more chronic diseases among the 16 selected conditions within a single individual and was categorised into five groups. A categorical variable was created to capture those with no multimorbidity (single disease only), two, three, four and five or more multimorbid conditions. Socio-demographic variables included age, sex, income and level of marginalisation. As prescription drug costs among Ontarians aged $<65$ years were primarily covered by private drug plans, we ran separate regressions for younger ( $<65$ years) and older (65+ years) cohorts, and also included a continuous variable for age in the models. Income level was categorised into five quintiles, with the lowest quintile reflecting the lowest income level. We used the Ontario Marginalisation Index, a validated censusbased and geographically based index, as a proxy for individual-level socio-demographic factors. ${ }^{32}$ The index consisted of four dimensions of marginalisation: material deprivation; residential instability; ethnic concentration and dependency. Lower scores on each dimension represent areas that are the least marginalised and higher scores represent areas that are the most marginalised. This index has been shown to be associated with several health outcomes. ${ }^{33}$

We also controlled for other factors that may confound the impact of multimorbidity on healthcare costs, such as the type of primary care model and geographic location. Selection of such factors was guided by previous healthcare cost studies ${ }^{12} 3435$ and was subject to the availability of data on these factors in Ontario administrative databases. The payment scheme of primary care services was categorised into three groups: group-based teams with capitation/salary and team-based payment (family health teams/other group models); capitation or blended payment models (family health networks/family health organisations) or primarily fee for service (family health groups and non-rostered patients). Lastly, we assigned a geographic location to each individual using the Rurality Index for Ontario, ${ }^{36}$ whereby a value $>40$ was considered to be a designated rural area.

\section{Analysis}

Annual healthcare costs per capita were described by health service sector, age group ( $<65 \mathrm{vs} \geq 65$ years), the degree of multimorbidity and each of the independent factors, such as sex, age group and level of marginalisation. Multivariate regression analyses were used to assess the incremental costs of interest in this study. To identify the regression model that best fits the cost data, we followed the steps suggested by Manning and Mullahy. ${ }^{37}$ We first ran OLS of the logarithmic transformation of cost data on the number of medical conditions and other confounding factors; however, the OLS regression was deemed inappropriate because the residuals were not normally distributed. Therefore, the generalised linear model (GLM) with a log-link function and a gamma distribution was chosen because a modified Park test suggested that the variance was proportional to the conditional mean. The GLM allows us to estimate mean healthcare costs without the need for retransformation.

Attributable costs due to multimorbidity were estimated by subtracting the mean predicted cost of one medical condition from the mean predicted cost of two 
conditions, two from three conditions, three from four conditions and four from at least five conditions, respectively. To investigate whether the relationship between the level of multimorbidity and healthcare costs was moderated by socio-demographic factors, we added two-way interaction terms between the level of multimorbidity and each socio-demographic factor, including sex, age, income level, deprivation quintile, instability quintile, dependency quintile and ethnic concentration quintile. The significance of interaction terms was assessed by comparing the likelihood ratio of the full model with all interaction terms with the model without interaction terms using the likelihood ratio test.

The model performance, including goodness of fit and specifications, was examined by checking the scaled deviance, Pearson's $\chi^{2}$ statistics and residual plots, respectively. All analyses were performed using SAS statistical software for UNIX (V.9.3; SAS Institute, Cary, North Carolina, USA).

\section{RESULTS}

We identified a cohort of 6639089 individuals living with at least one of the selected 16 medical conditions in Ontario in 2009 (see online supplementary appendix 2 for baseline characteristics). Our cohort represents about $50 \%$ of the total population in the province of Ontario in 2009. Close to half of the study cohort (48\%) had at least two selected medical conditions, and this prevalence was found to increase with age. The majority of the study cohort was younger than 65 years of age $(75 \%)$ and just over half was female (53\%). Nearly all individuals (91\%) resided in non-rural areas, and about one-third (33\%) lived in neighbourhoods with a high proportion of diverse ethnic groups.
The total annual healthcare cost estimated for the study cohort was $\mathrm{C} \$ 26.5$ billion. As shown in figure 1, individuals living with at least two selected medical conditions represented $24.4 \%$ of the total population of Ontario ( 13 million) but accounted for approximately two-thirds $(67.9 \%)$ of total allocatable healthcare costs in 2009/2010. By contrast, individuals without multimorbidity who accounted for $76 \%$ of the total population were responsible for only $32.1 \%$ of total allocatable healthcare costs. On average, annual total costs per capita amounted to $\mathrm{C} \$ 2217$ in individuals $<65$ years and $\mathbf{C} \$ 9398$ in those aged 65 years or older.

Table 1 shows the annual total costs per capita by baseline characteristics for young and older adults. For both age groups, per capita total healthcare costs were higher in women than in men. The average healthcare costs increased with older age, and greater levels of marginalisation were associated with higher healthcare costs in both age groups. Mean total healthcare costs were the highest among individuals living in the most deprived and most unstable areas as well as those who were highly dependent; however, mean total costs decreased as income level increased.

Figure 2 illustrates the distribution of total cost per capita by type of services. Among individuals $<65$ years, hospitalisation was the primary cost driver and responsible for $47 \%$ of total healthcare costs, followed by physician costs $(32 \%)$, drug costs (10\%) and continuing care costs $(6 \%)$. For older adults, hospital costs remained the largest cost component $(41 \%)$, followed by continuing care costs $(23 \%)$, drug costs $(19 \%)$ and physician costs $(15 \%)$. Figure 2 also reveals that unadjusted mean total costs increased with additional numbers of medical conditions, ranging from $\mathrm{C} \$ 1352$ in individuals $<65$ years without multimorbidity to $C \$ 13105$ in those living with

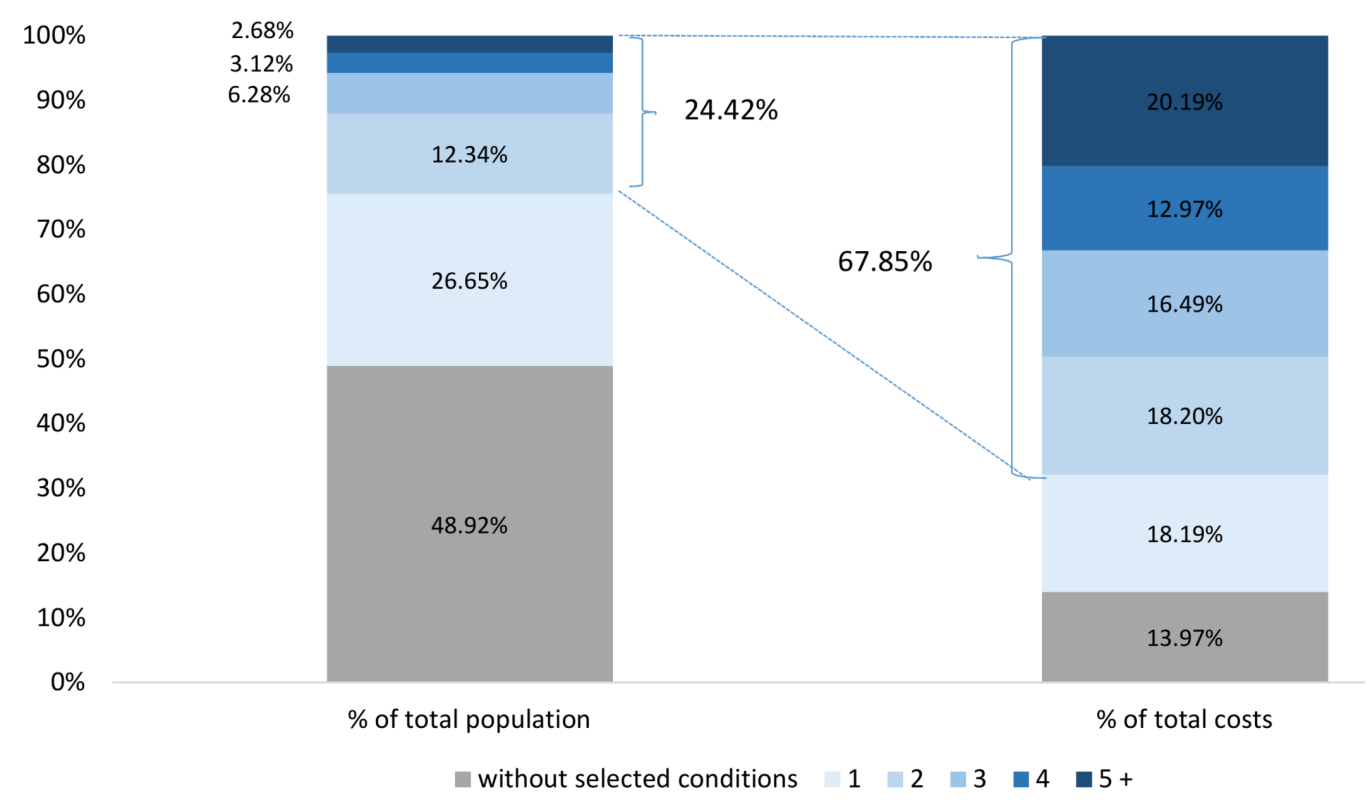

Figure 1 Distribution of total number of population and total health system costs in Ontario from 1 April 2009 to 31 March 2010. 
Table 1 Annual per capita healthcare costs by baseline characteristics and age group, 1 April 2009 to 31 March 2010

$<65$ years
$(\mathrm{n}=5004699)$

Per capita healthcare cost (C\$)

N

All cohort

5004699

Sex

\begin{tabular}{ll} 
Female & 2618591 \\
\hline Male & 2386108 \\
\hline
\end{tabular}

Age group (years)

$\begin{array}{llll}<20 & 809782 & \begin{array}{l}997 \\ (6420)\end{array} & \begin{array}{l}257 \\ (103-600)\end{array} \\ 20-44 & 1784314 & \begin{array}{l}1835 \\ (7997)\end{array} & 440 \\ & & (155-1171) \\ 45-64 & 3247243 & 2910 & 684 \\ & & (11414) & (291-1725)\end{array}$

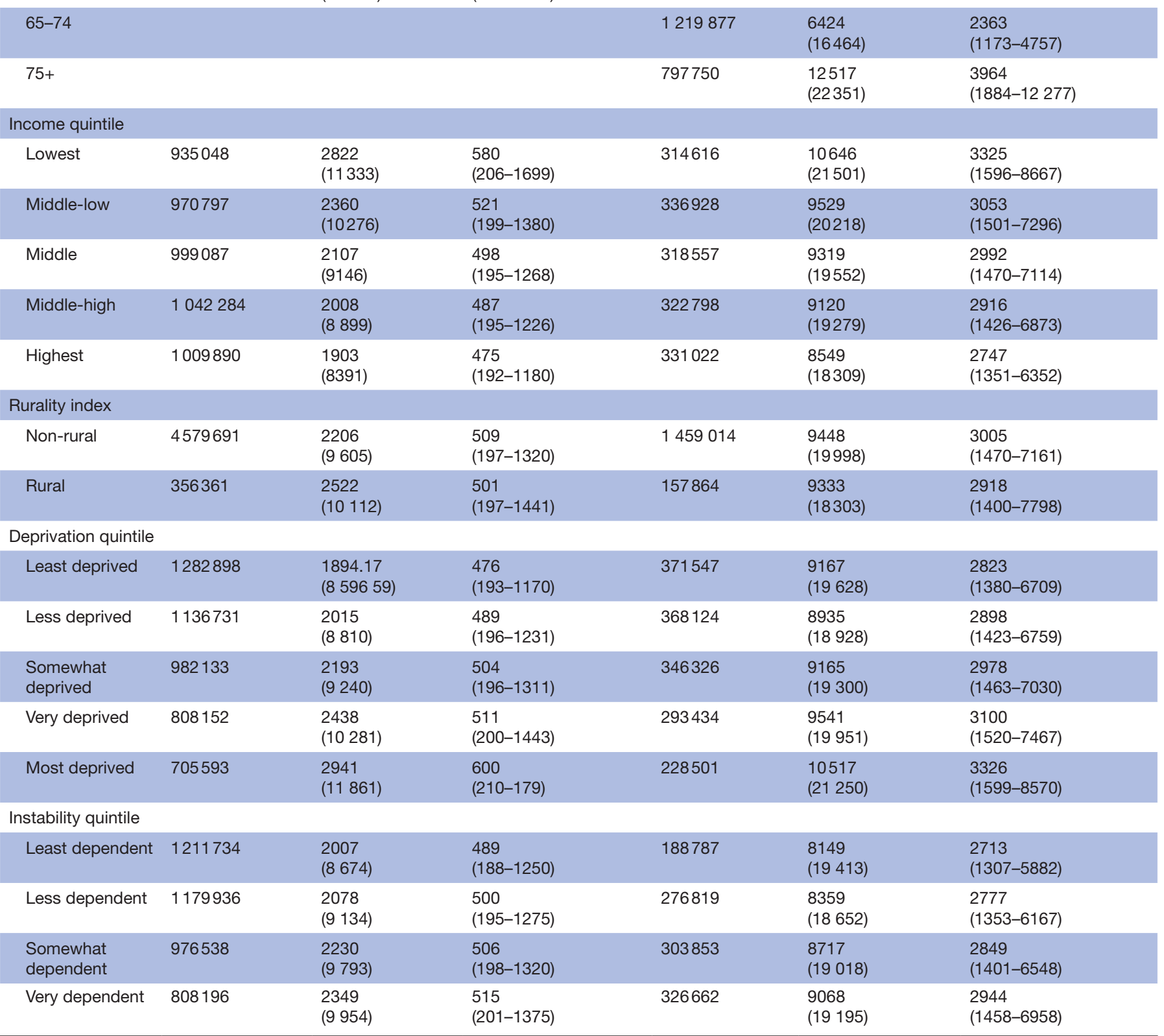

Continued

$\geq 65$ years

$(n=1634390)$
N

1634390

923053

711337

378.67

(132-1058)
(1926.96

(19 245)

9230.31

(20488)
2991.97

(1461-7344)

2968.13

(1431-6982) 


\begin{tabular}{|c|c|c|c|c|c|c|}
\hline & \multicolumn{3}{|c|}{$\begin{array}{l}<65 \text { years } \\
(n=5004699)\end{array}$} & \multicolumn{3}{|c|}{$\begin{array}{l}\geq 65 \text { years } \\
(n=1634390)\end{array}$} \\
\hline & \multirow[b]{2}{*}{$\mathbf{N}$} & \multicolumn{2}{|c|}{ Per capita healthcare cost (C\$) } & \multirow[b]{2}{*}{$\mathbf{N}$} & \multicolumn{2}{|c|}{ Per capita healthcare cost (C\$) } \\
\hline & & Mean (SD) & Median (IQR) & & Mean (SD) & Median (IQR) \\
\hline Most dependent & 739103 & $\begin{array}{l}2650 \\
(10947)\end{array}$ & $\begin{array}{l}550 \\
(213-1507)\end{array}$ & 511811 & $\begin{array}{l}10961 \\
(20953)\end{array}$ & $\begin{array}{l}3381 \\
(1636-9336)\end{array}$ \\
\hline \multicolumn{7}{|c|}{ Ethnic concentration quintile } \\
\hline Lowest & 564476 & $\begin{array}{l}2398 \\
(9766)\end{array}$ & $\begin{array}{l}500 \\
(200-1370)\end{array}$ & 283980 & $\begin{array}{l}9309 \\
(18529)\end{array}$ & $\begin{array}{l}2983 \\
(1463-7533)\end{array}$ \\
\hline Middle-low & 756120 & $\begin{array}{l}2288 \\
(9552)\end{array}$ & $\begin{array}{l}491 \\
(196-1317)\end{array}$ & 304526 & $\begin{array}{l}9170 \\
(18773)\end{array}$ & $\begin{array}{l}2969 \\
(1458-7283)\end{array}$ \\
\hline Middle & 854573 & $\begin{array}{l}2280 \\
(9780)\end{array}$ & $\begin{array}{l}497 \\
(196-1317)\end{array}$ & 305524 & $\begin{array}{l}9540 \\
(19678)\end{array}$ & $\begin{array}{l}3011 \\
(1478-7419)\end{array}$ \\
\hline Middle-high & 1028876 & $\begin{array}{l}2190 \\
(9565)\end{array}$ & $\begin{array}{l}502 \\
(195-1309)\end{array}$ & 294164 & $\begin{array}{l}9600 \\
(20240)\end{array}$ & $\begin{array}{l}3012 \\
(1473-7266)\end{array}$ \\
\hline Highest & 1711462 & $\begin{array}{l}2124 \\
(9468)\end{array}$ & $\begin{array}{l}528 \\
(199-1331)\end{array}$ & 419738 & $\begin{array}{l}9288 \\
(20751)\end{array}$ & $\begin{array}{l}2981 \\
(1441-6694)\end{array}$ \\
\hline
\end{tabular}

five or more medical conditions, corresponding to a 10-fold increase. On the other hand, while C\$4185 was spent on older adults without multimorbidity, spending increased by about fivefold to C $\$ 19196$ in those living with five or more medical conditions.

Table 2 shows adjusted attributable costs of multimorbidity after controlling for other factors. Among individuals $<65$ years, the attributable total cost was C\$377 in those living with two medical conditions and C\$2073 in those living with at least five medical conditions, corresponding to a sixfold increase in attributable cost. Similarly, attributable total costs in older adults also rose with increasing number of medical conditions, ranging from
C\$1026 in those with two medical conditions to C\$3831 in those with five or more. The magnitude of an incremental cost, however, depended on the reference category. Specifically, one additional medical condition in young adults without multimorbidity led to an attributable cost of C\$377, while for young adults who already had three medical conditions, one additional health condition resulted in a total cost of $\mathrm{C} \$ 798$. These incremental costs were even greater in older adults, among whom the incremental cost rose from C\$1026 (one vs two conditions) to $\mathrm{C} \$ 1652$ (three vs four conditions). Similar patterns were observed for subdivided healthcare costs, which varied across age groups (table 2). An additional

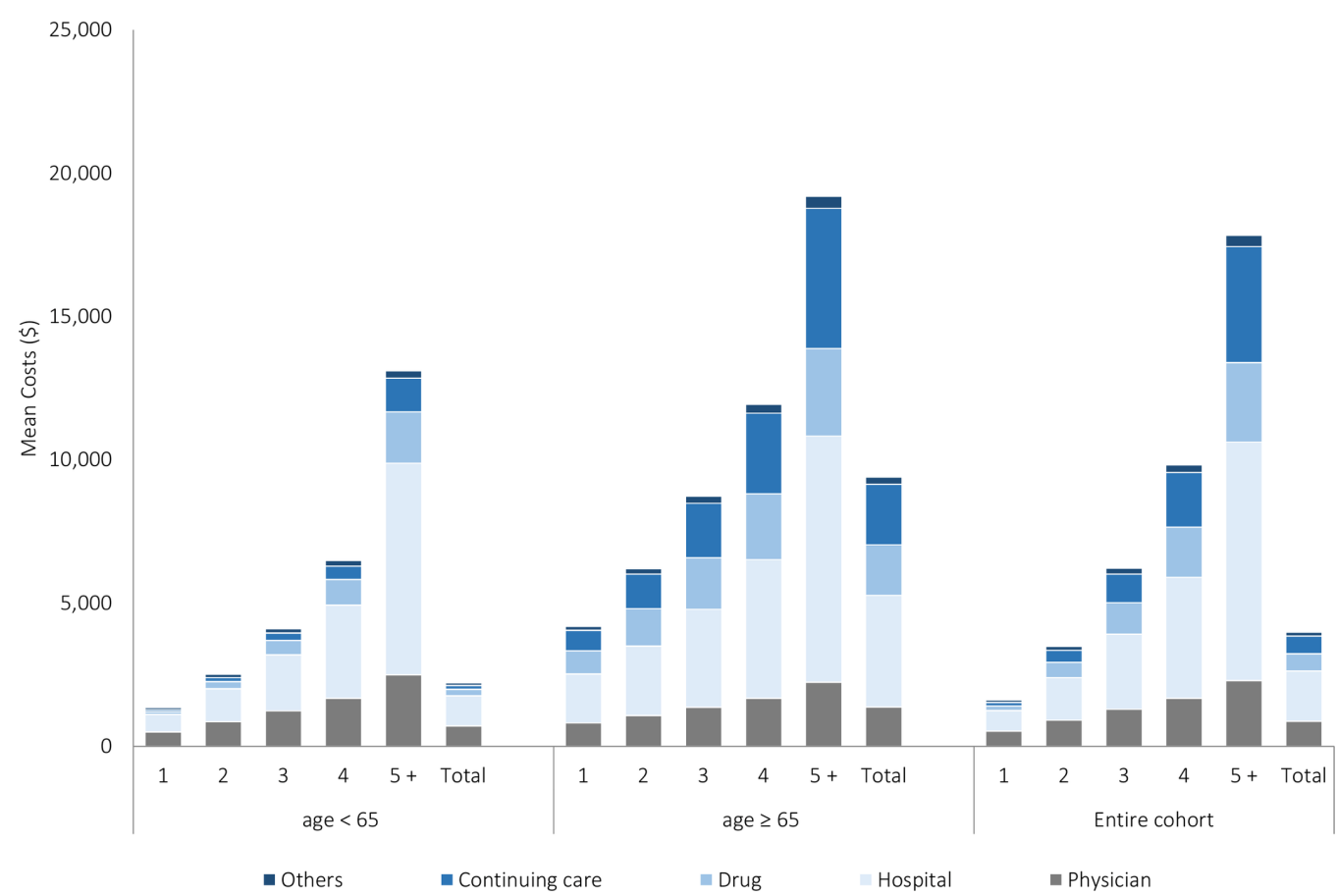

Figure 2 Unadjusted mean total healthcare cost per capita for Ontario adults, by service type, number of conditions and age group from 1 April 2009 to 31 March 2010. 


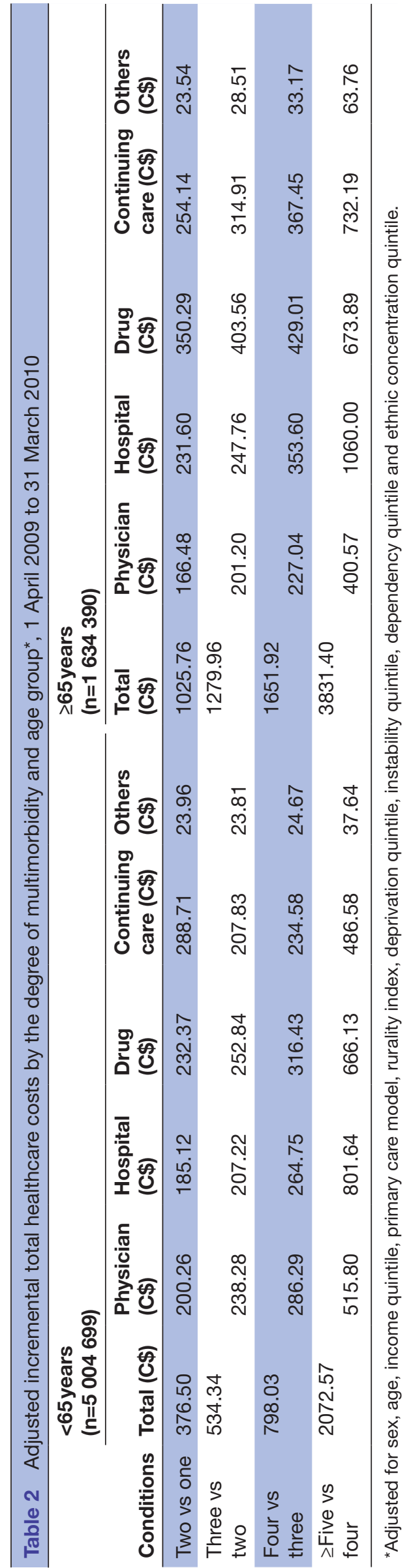

medical condition caused a onefold to threefold increase in the costs of each health sector except for hospital care, for which incremental costs increased steadily from $\mathrm{C} \$ 185$ to $\mathrm{C} \$ 802$ in the younger cohort and $\mathrm{C} \$ 232$ to $\mathrm{C} \$ 1060$ in the older adult cohort.

We also found that the association between the number of medical conditions (ie, the degree of multimorbidity) and healthcare costs was significantly modified by age and sex for both young and older adults (table 3), and the positive association between healthcare costs and levels of multimorbidity was significantly stronger for older than younger adults. For individuals aged 65 years or younger, the increase in healthcare costs was more gradual in women than in their male counterparts, however, among those aged 65 years or older, the increase in healthcare costs in women was significantly greater than in men.

For both age groups, we observed small interaction effects between the number of medical conditions and other socio-demographic factors. The rise in healthcare costs as the level of multimorbidity increased was less pronounced among high-income individuals than low-income individuals, and the association between the level of multimorbidity and healthcare costs was significantly modified by the level of deprivation, instability, dependency and ethnic concentration. The positive association between the level of multimorbidity and healthcare costs was stronger among individuals living in more deprived, unstable, dependent or diverse ethnic groups than those living in less deprived, stable, dependent or high concentration of ethnic diversity areas. We did not observe a significant interaction between the number of medical conditions and the level of dependency in the older adult cohort.

\section{DISCUSSION}

Individuals living with multimorbidity accounted for $79 \%$ of total healthcare costs incurred by our study cohort and $68 \%$ of total allocatable healthcare costs in Ontario in 2009. Although there is a growing body of literature documenting the economic burden of multimorbidity in other jurisdictions, ${ }^{12} 1338$ the current study provides further evidence that the relatively small proportion of the population with multimorbid conditions is responsible for a disproportionately high percentage of total healthcare costs. Moreover, we observed this disproportionate relationship in both young ( $<65$ years) and $(65+$ years $)$ older cohorts, suggesting that any approaches to containing the healthcare costs of multimorbidity should be implemented across all age groups.

Our study demonstrated that healthcare costs increased significantly with higher levels of multimorbidity, and that this positive association exists even after the adjustment for confounding factors and a skewed distribution of cost data using the generalised linear model with a log link function and a gamma distribution. The exponential relationship between multimorbidity and incremental healthcare costs shown in this study suggests that 
Table 3 Generalised linear models results for total healthcare costs $\dagger$

\begin{tabular}{|c|c|c|c|c|}
\hline & \multicolumn{2}{|c|}{$\begin{array}{l}<65 \text { years } \\
(n=5004699)\end{array}$} & \multicolumn{2}{|c|}{$\begin{array}{l}\geq 65 \text { years } \\
(n=1634390)\end{array}$} \\
\hline & Coefficient & SE & Coefficient & SE \\
\hline Intercept & $1.6844^{\star * *}$ & 0.0007 & $1.6049^{\star \star \star}$ & 0.0034 \\
\hline Age & $0.0023^{\star * \star}$ & 0.0001 & $0.0053^{* \star *}$ & 0.0001 \\
\hline \multicolumn{5}{|l|}{ Sex } \\
\hline Male & Reference & & Reference & \\
\hline Female & $0.0628^{\star \star *}$ & 0.0002 & $-0.0023^{\star \star \star}$ & 0.0006 \\
\hline \multicolumn{5}{|c|}{ Number of medical conditions } \\
\hline One condition & Reference & & Reference & \\
\hline Two conditions & $0.1092^{\star \star \star}$ & 0.0017 & $0.1068^{\star * \star}$ & 0.0044 \\
\hline Three conditions & $0.2189^{\star \star \star}$ & 0.0027 & $0.1860^{\star \star \star}$ & 0.0045 \\
\hline Four conditions & $0.3312^{\star \star \star}$ & 0.0050 & $0.2563^{\star \star \star}$ & 0.0049 \\
\hline$\geq$ Five conditions & $0.4203^{* * *}$ & 0.0080 & $0.3772^{\star * \star}$ & 0.0048 \\
\hline \multicolumn{5}{|l|}{ Income quintile } \\
\hline Lowest & Reference & & Reference & \\
\hline Middle-low & $-0.0043^{\star \star \star}$ & 0.0005 & $-0.0019^{*}$ & 0.0010 \\
\hline Middle & $-0.0045^{\star \star \star}$ & 0.0005 & 0.00014 & 0.0012 \\
\hline Middle-high & $-0.0044^{\star \star \star}$ & 0.0006 & 0.0001 & 0.0012 \\
\hline Highest & $-0.0080^{\star \star \star}$ & 0.0006 & $-0.0045^{\star \star \star}$ & 0.0013 \\
\hline \multicolumn{5}{|l|}{ Deprivation quintile } \\
\hline Least deprived & Reference & & Reference & \\
\hline Less deprived & $-0.0006^{\star}$ & 0.0004 & $-0.0014^{\star \star \star}$ & 0.0008 \\
\hline Somewhat deprived & $-0.0008^{\star}$ & 0.0004 & $-0.0020^{\star \star}$ & 0.0009 \\
\hline Very deprived & $0.0022^{\star \star \star}$ & 0.0005 & -0.0009 & 0.0011 \\
\hline Most deprived & $0.0135^{\star \star \star}$ & 0.0006 & $0.0044^{\star * *}$ & 0.0013 \\
\hline \multicolumn{5}{|l|}{ Instability quintile } \\
\hline Least unstable & Reference & & Reference & \\
\hline Less unstable & $0.0039^{\star \star \star}$ & 0.0005 & $-0.0019^{\star \star}$ & 0.0009 \\
\hline Somewhat unstable & $0.0073^{\star \star \star}$ & 0.0005 & -0.0008 & 0.0009 \\
\hline Very unstable & $0.0122^{\star \star \star}$ & 0.0005 & $0.0031^{\star \star \star}$ & 0.0009 \\
\hline Most unstable & $0.0247^{\star \star \star}$ & 0.0005 & $0.0087^{\star \star \star}$ & 0.0010 \\
\hline \multicolumn{5}{|c|}{ Ethnic concentration quintile } \\
\hline Lowest & Reference & & Reference & \\
\hline Middle-low & 0.0002 & 0.0004 & -0.0005 & 0.0009 \\
\hline Middle & $0.0018^{* * *}$ & 0.0004 & 0.0022 & 0.0009 \\
\hline Middle-high & $0.0047^{\star \star \star}$ & 0.0004 & -0.0007 & 0.0010 \\
\hline Highest & $0.0066^{\star \star \star}$ & 0.0004 & $-0.0043^{\star \star \star}$ & 0.0009 \\
\hline \multicolumn{5}{|l|}{ Dependency quintile } \\
\hline Least dependent & Reference & & Reference & \\
\hline Less dependent & 0.0004 & 0.0004 & $0.0012^{\star \star}$ & 0.0005 \\
\hline Somewhat dependent & 0.0001 & 0.0004 & $0.0027^{\star \star *}$ & 0.0005 \\
\hline Very dependent & $0.0009^{\star \star}$ & 0.0004 & $0.0030^{\star \star \star}$ & 0.0005 \\
\hline Most dependent & $0.0020^{\star \star \star}$ & 0.0005 & $0.0100^{\star \star \star}$ & 0.0005 \\
\hline \multicolumn{5}{|c|}{ Number of medical conditions * sex } \\
\hline One condition* male & Reference & & Reference & \\
\hline
\end{tabular}


Table 3 Continued

\begin{tabular}{|c|c|c|c|c|}
\hline & \multicolumn{2}{|c|}{$\begin{array}{l}<65 \text { years } \\
(n=5004699)\end{array}$} & \multicolumn{2}{|c|}{$\begin{array}{l}\geq 65 \text { years } \\
(n=1634390)\end{array}$} \\
\hline & Coefficient & SE & Coefficient & SE \\
\hline Two conditions * female & $-0.0171^{\star \star \star}$ & 0.0016 & $-0.0029^{\star \star \star}$ & 0.0007 \\
\hline Three conditions * female & $-0.0396^{\star \star \star}$ & 0.0011 & $-0.0022^{\star \star \star}$ & 0.0008 \\
\hline Four conditions * female & $-0.0549^{\star \star \star}$ & 0.0007 & 0.0001 & 0.0008 \\
\hline$\geq$ Five conditions * female & $-0.0659^{\star \star \star}$ & 0.0005 & $0.0030^{\star \star \star}$ & 0.0008 \\
\hline \multicolumn{5}{|l|}{ Number of medical conditions * age } \\
\hline One condition * age & Reference & & Reference & \\
\hline Two conditions * age & $-0.0007^{\star \star \star}$ & 0.0016 & $-0.0006^{\star \star \star}$ & 0.0001 \\
\hline Three conditions * age & $-0.0014^{\star \star \star}$ & 0.0011 & $-0.0010^{\star \star \star}$ & 0.0001 \\
\hline Four conditions * age & $-0.0022^{\star \star \star}$ & 0.0007 & $-0.0014^{\star \star \star}$ & 0.0001 \\
\hline$\geq$ Five conditions * age & $-0.0023^{\star \star \star}$ & 0.0005 & $-0.0023^{\star \star \star}$ & 0.0001 \\
\hline \multicolumn{5}{|c|}{ Number of medical conditions * income quintile } \\
\hline One condition* lowest & Reference & & Reference & \\
\hline Two conditions*middle-low & $-0.0016^{\star}$ & 0.0009 & $-0.0025^{\star}$ & 0.0013 \\
\hline Three conditions * middle-low & -0.0011 & 0.0013 & $-0.0037^{\star \star}$ & 0.0014 \\
\hline Four conditions` middle-low & $-0.0043^{\star \star}$ & 0.0020 & $-0.0043^{\star *}$ & 0.0015 \\
\hline$\geq$ Five conditions ${ }^{\star}$ middle-low & -0.0031 & 0.0027 & $-0.0046^{\star \star}$ & 0.0014 \\
\hline Two conditions*middle & $-0.0020^{\star \star}$ & 0.0010 & $-0.0032^{\star \star}$ & 0.0015 \\
\hline Three conditions * middle & $-0.0030^{\star *}$ & 0.0014 & $-0.0051^{\star \star}$ & 0.0015 \\
\hline Four conditions* middle & $-0.0053^{\star \star}$ & 0.0023 & $-0.0055^{\star \star}$ & 0.0017 \\
\hline$\geq$ Five conditions ${ }^{\star}$ middle & -0.0028 & 0.0031 & $-0.0072^{\star \star \star}$ & 0.0016 \\
\hline Two conditions*middle-high & $-0.0024^{\star \star}$ & 0.0011 & $-0.0031^{*}$ & 0.0016 \\
\hline Three conditions * middle-high & $-0.0032^{\star \star}$ & 0.0016 & $-0.0052^{\star *}$ & 0.0016 \\
\hline Four conditions ${ }^{\star}$ middle-high & $-0.0067^{\star \star}$ & 0.0025 & $-0.0081^{\star \star \star}$ & 0.0018 \\
\hline$\geq$ Five conditions ${ }^{\star}$ middle-high & $-0.0093^{\star \star}$ & 0.0034 & $-0.0070^{\star \star \star}$ & 0.0018 \\
\hline Two conditions*highest & -0.0015 & 0.0011 & $-0.0036^{\star \star}$ & 0.0017 \\
\hline Three conditions *highest & $-0.0031^{*}$ & 0.0017 & $-0.0063^{\star \star \star}$ & 0.0018 \\
\hline Four conditions ${ }^{*}$ highest & $-0.0096^{\star \star \star}$ & 0.0027 & $-0.0088^{\star \star \star}$ & 0.0019 \\
\hline Five conditions ${ }^{*}$ highest & $-0.0099^{\star \star}$ & 0.0038 & $-0.0095^{\star \star \star}$ & 0.0019 \\
\hline \multicolumn{5}{|c|}{ Number of medical conditions * deprivation quintile } \\
\hline One condition* lowest & Reference & & Reference & \\
\hline Two conditions*middle-low & $0.0024^{\star \star \star}$ & 0.0007 & -0.0001 & 0.0011 \\
\hline Three conditions * middle-low & $0.0038^{* * *}$ & 0.0010 & -0.0015 & 0.0011 \\
\hline Four conditions* middle-low & 0.0027 & 0.0017 & -0.0016 & 0.0013 \\
\hline$\geq$ Five conditions ${ }^{*}$ middle-low & $0.0060^{* *}$ & 0.0026 & $-0.0029^{* *}$ & 0.0012 \\
\hline Two conditions*middle & $0.0047^{\star \star \star}$ & 0.0007 & -0.0002 & 0.0012 \\
\hline Three conditions * middle & $0.0067^{\star \star *}$ & 0.0010 & -0.0018 & 0.0013 \\
\hline Four conditions* middle & $0.0062^{\star \star \star}$ & 0.0017 & $-0.0045^{\star \star}$ & 0.0014 \\
\hline$\geq$ Five conditions ${ }^{\star}$ middle & $0.0109^{\star \star \star}$ & 0.0026 & $-0.0042^{\star \star}$ & 0.0014 \\
\hline Two conditions*middle-high & $0.0057^{\star \star \star}$ & 0.0009 & -0.0012 & 0.0014 \\
\hline Three conditions * middle-high & $0.0071^{\star \star \star}$ & 0.0014 & $-0.0031^{\star \star}$ & 0.0015 \\
\hline Four conditions* middle-high & $0.0074^{\star \star \star}$ & 0.0022 & $-0.0051^{\star *}$ & 0.0016 \\
\hline$\geq$ Five conditions ${ }^{\star}$ middle-high & $0.0111^{\star * *}$ & 0.0032 & $-0.0079^{\star * *}$ & 0.0016 \\
\hline Two conditions*highest & $0.0073^{\star \star \star}$ & 0.0011 & -0.0028 & 0.0017 \\
\hline
\end{tabular}

Continued 
Table 3 Continued

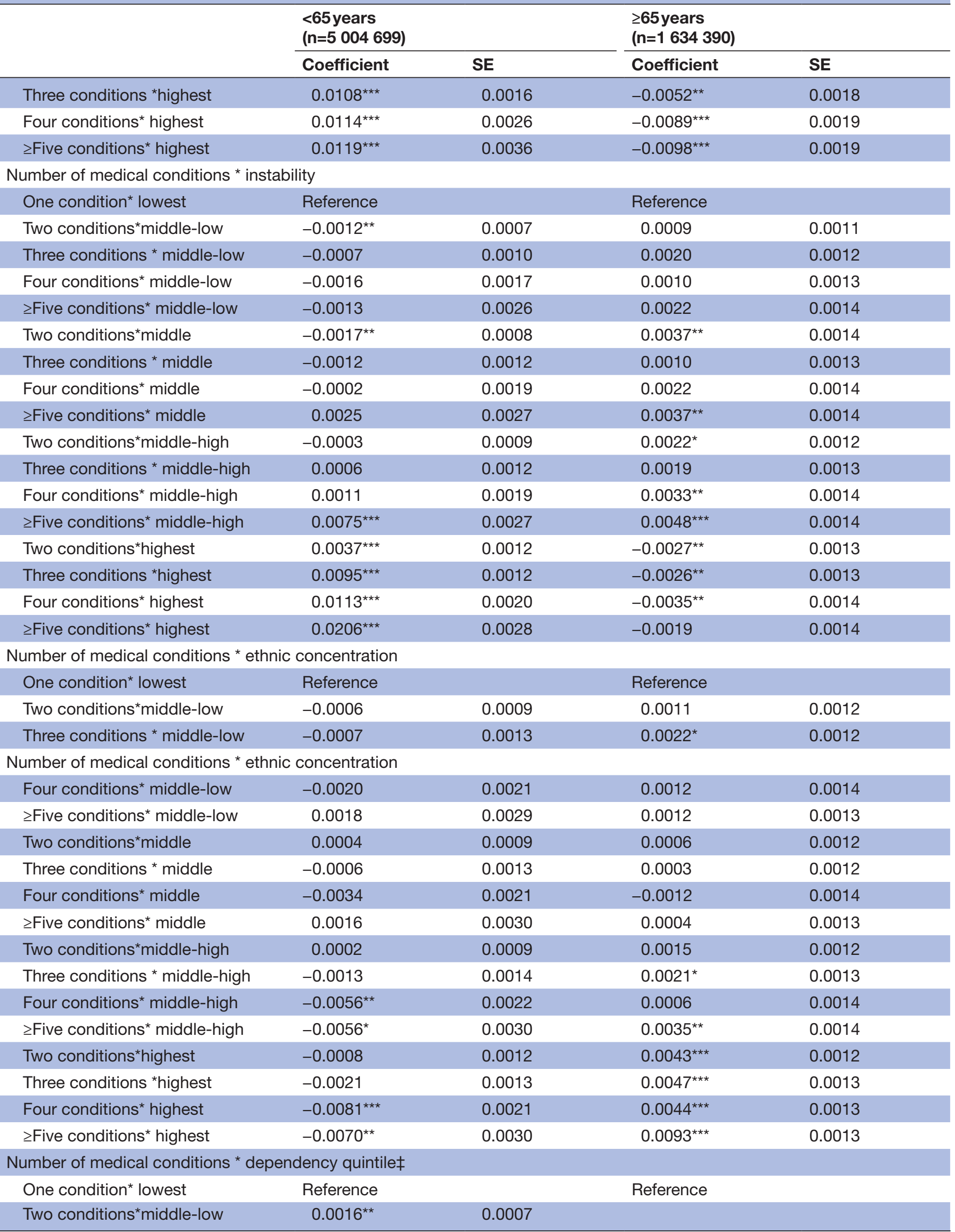




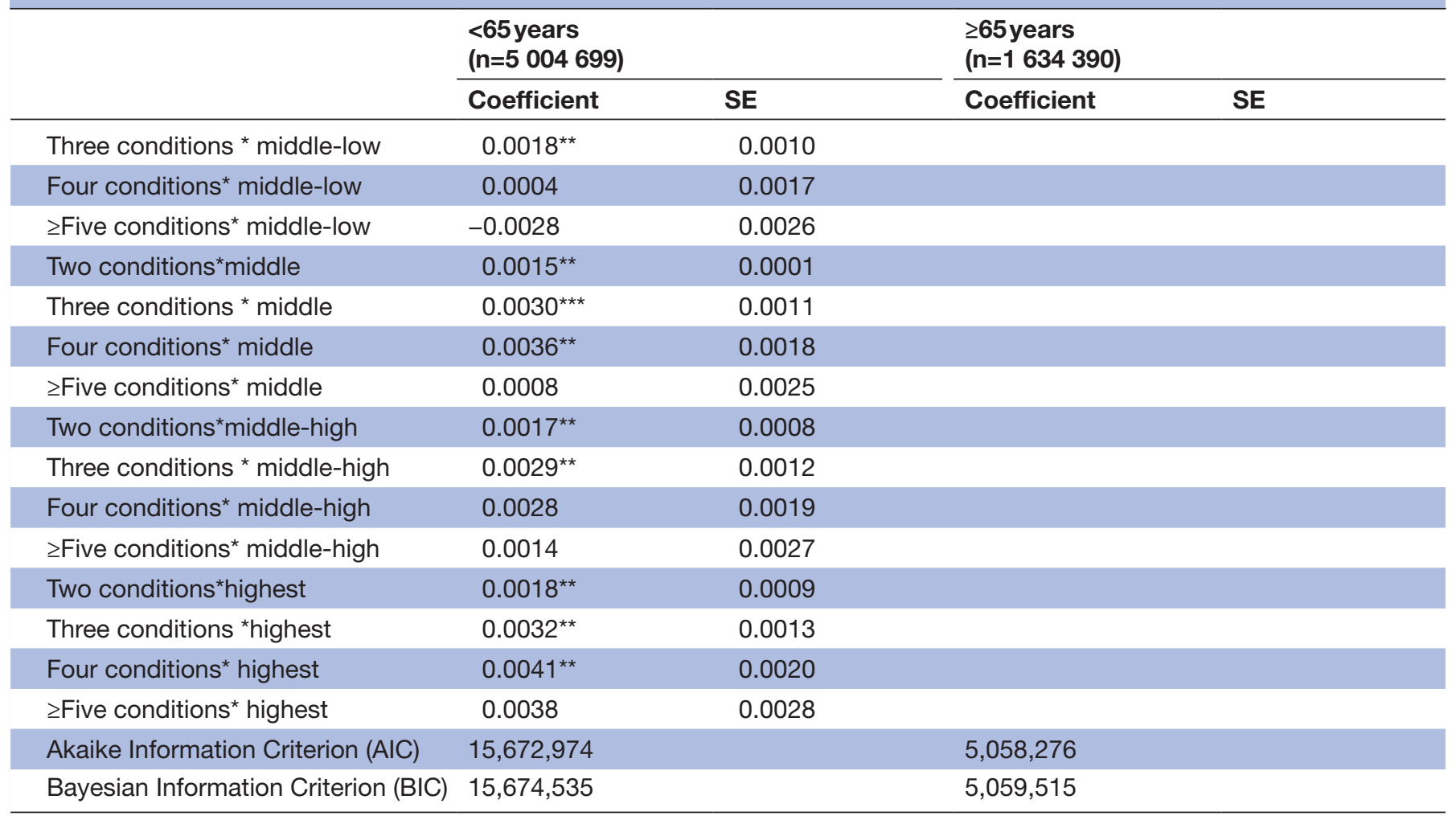

${ }^{* * *} \mathrm{p}<0.001,{ }^{* *} \mathrm{p}<0.05,{ }^{*} \mathrm{p}<0.10$.

†Adjusted for primary care models and rurality index.

łInteraction between the number of medical conditions and dependency quintile was not statistically significant and therefore excluded from a final model.

the financial burden of multimorbidity to the healthcare system is not simply equal to the sum of costs incurred by each individual condition. This non-linearity reflects the complex association of the degree of multimorbidity, the type of disease clusters and healthcare costs. It is likely that patients with multimorbidity might experience worse health outcomes and require more complex clinical management. ${ }^{9}$ They are also vulnerable to receiving redundant diagnostic tests, ${ }^{12}$ a suboptimal level of continuity of care and inappropriate prescriptions, ${ }^{11}$ as current treatment guidelines are mainly focused on individual disease management. ${ }^{10}$ Thus, as the number of healthcare providers involved in the patient's care increases, information sharing and coordinating care across healthcare providers may become increasingly challenging. ${ }^{39}$ Moreover, an increasing number of comorbid conditions may compromise patients' ability to self-manage their diseases. ${ }^{40}$ Therefore, the high healthcare spending on multimorbidity found in our study underscores the need for ensuring continuity and coordination of care in this population.

More importantly, our study contributes to the understanding of the association between the degree of multimorbidity and healthcare costs. We observed that each unit increase in age amplified the rise in healthcare costs associated with an increasing number of medical conditions. The observed interaction effect may partly be due to patterns in healthcare use among the older population, which is often characterised by polypharmacy and the use of continuing care services that are very costly. Additionally, we found that the positive association between healthcare costs and levels of multimorbidity was stronger in men than in women among individuals $<65$ years. This sex difference might relate to the prevalence of different disease clusters in men and women, as men within this age group often experience life-threatening and more serious illnesses than women. ${ }^{414}$ For those $>65$ years, the increase in healthcare costs observed with the increase in the level of multimorbidity was significantly higher in women than men. This sex difference could be partially explained by longer life expectancy and greater risk of multimorbidity in older women than men, ${ }^{20} 43$ which may cause older women to be more dependent on formal (paid) healthcare services and other informal (unpaid) caregivers.

We observed small interaction effects of neighbourhood-level socioeconomic characteristics on the association between the number of medical conditions and healthcare costs. Living in lower income and marginalised areas, that is, areas with greater levels of instability, dependency or ethnic concentration, accelerated the increase in health system costs with increased multimorbidity. This may reflect a higher risk of experiencing more complex multimorbid conditions among individuals living in 
disadvantaged neighbourhoods, ${ }^{44}$ in turn leading to greater demand for and utilisation of healthcare. Another plausible explanation for this phenomenon is that individuals living in more deprived areas may face barriers to accessing health services ${ }^{45}$ and therefore have delayed access to preventive healthcare interventions or treatments, ${ }^{46}$ consequently being at greater risk of developing poorer health outcomes and incurring higher healthcare costs. The effects of socioeconomic factors reported in this study should however be interpreted with caution, as they were derived based on neighbourhood. Although the interaction terms between socioeconomic factors and levels of multimorbidity were statistically significant, most of the estimated effect sizes were very small and may be a result of the large sample size used in this study.

\section{Strengths and limitations}

This population-based study was based on a large sample size and used robust costing and generalised linear model regression techniques. The availability of linked and patient-level health administrative databases allowed the estimation of the total health system costs associated with multimorbidity from all healthcare sectors, and the use of health administrative databases minimised potential recall and non-response biases that are commonly found in survey data.

Nonetheless, the results of this study should be interpreted in light of the following limitations. First, we estimated healthcare costs based on 16 selected medical conditions, and this selection of a limited number of medical conditions is likely to underestimate the overall healthcare costs of multimorbidity. However, total cost estimates reported in our study were comprehensive, as they amounted to $86 \%$ of total allocatable government expenditures in Ontario in $2009 .{ }^{47}$ Second, due to a paucity of data, certain costs (eg, deductibles and copayments borne by supplemental health insurance, out-ofpocket beneficiary payments and indirect costs associated with caregiving) were excluded from the analysis. In addition, this study could not capture the costs of medications covered by private sectors, including private insurers and out-of-pocket expenses, which at the time of the study represented the largest component of total prescription drug costs of Canadians who are aged $<65$ years. ${ }^{48}$ For this reason, findings from this study may not be generalisable to other jurisdictions with different healthcare systems.

Third, this study did not take into account clusters of medical conditions. It is possible that the relationship between multimorbidity and healthcare costs may vary according to the type and patterns of comorbid medical conditions, which should be investigated in future studies. We chose to use disease counts in the present study, as there are no standards or guidelines for the definition or measurement of multimorbidity, and the choice of the measure would be subject to data availability and the outcome of interest. ${ }^{49}{ }^{50}$ A previous study conducted by our team ${ }^{5}$ has shown, however, that there was no common clustering of diseases among individuals living with multimorbidity, as the number of disease clusters required to include $80 \%$ of the study population increased from 14 (among individuals with two conditions) to 2744 clusters of conditions (among individuals with five or more conditions), thus supporting the use of disease counts rather than clusters. Moreover, a previous systematic review showed that 132 definitions of multimorbidity with 1631 criteria were used in the published literature. ${ }^{51}$ Our decision to use disease counts is also supported by a study by Islam $e t a \tilde{p}^{2}$ indicating that the total number of chronic conditions were more predictive of out-of-pocket healthcare costs and high-cost users than disease clusters, dominant groups or dominant pairs.

\section{CONCLUSION}

This population-based, retrospective cohort study highlights the amount by which health system costs increased significantly with increasing levels of multimorbidity in a publicly financed healthcare system. The average and incremental healthcare costs reported in this study could serve as the foundation for future health economic evaluation of interventions for preventing and managing multimorbidity. As the relationship between multimorbidity and healthcare costs varies according to socio-demographic factors, interventions addressing disparities in healthcare in individuals living with multimorbidity may have the potential to reduce total health system costs.

\section{Author affiliations}

${ }^{1}$ Ottawa Hospital Research Institute, The Ottawa Hospital, Ottawa, Canada

${ }^{2}$ School of Epidemiology, Public Health and Preventive Medicine, University of Ottawa, Ottawa, Canada

${ }^{3}$ Institute for Clinical Evaluative Sciences, Toronto, Canada

${ }^{4}$ Schools of Pharmacy, University of Waterloo, Ontario, Canada

${ }^{5}$ Institute of Health Policy, Management and Evaluation, University of Toronto, Toronto, Ontario, Canada

${ }^{6}$ Women's College Research Institute, Women's College Hospital, Toronto, Canada ${ }^{7}$ Department of Family Medicine, University of Alberta, Alberta, Canada ${ }^{8}$ Department of Health Sciences, Lakehead University, Thunder Bay, Canada ${ }^{9}$ Dalla Lana School of Public Health, University of Toronto, Toronto, Canada

${ }^{10}$ Toronto Rehabilitation Institute, Toronto, Canada

Contributors WPW was the lead for the conception and creation of the cohort. $Y B$ created the cohorts through data linkages and helped with data analysis and methods. KT and WW drafted the manuscript. KT, CM, AG, SB, AK, YB, YP and WPW interpreted the results and revised the manuscript for important intellectual content. All authors read and approved the final manuscript.

Funding This manuscript was supported through the Health System Performance Research Network (HSPRN) by a grant from the Ontario Ministry of Health and LongBTerm Care (MOHLTC grant \#06034) and through provision of data by the Institute for Clinical and Evaluative Sciences with funding from an annual grant by the Ministry of Health and LongBTerm Care. The opinions, results and conclusions reported in this paper are those of the authors and are independent of the funding sources. No endorsement by the Institute for Clinical Evaluative Sciences or Ontario MOHLTC is intended or should be inferred. At the time this research was conducted, Dr Thavorn was partially supported by the HSPRN postBdoctoral award and the Li Ka Shing postBdoctoral award. None of the authors have any conflicts of interest to report.

Competing interests None declared.

Ethics approval Research Ethics Board at Sunnybrook Health Sciences Centre, Toronto, Ontario, Canada.

Provenance and peer review Not commissioned; externally peer reviewed. 
Data sharing statement No additional data are available.

Open Access This is an Open Access article distributed in accordance with the Creative Commons Attribution Non Commercial (CC BY-NC 4.0) license, which permits others to distribute, remix, adapt, build upon this work non-commercially, and license their derivative works on different terms, provided the original work is properly cited and the use is non-commercial. See: http://creativecommons.org/ licenses/by-nc/4.0/

(C) Article author(s) (or their employer(s) unless otherwise stated in the text of the article) 2017. All rights reserved. No commercial use is permitted unless otherwise expressly granted.

\section{REFERENCES}

1. van den Akker M, Buntinx F, Metsemakers JF, et al. Multimorbidity in general practice: prevalence, incidence, and determinants of co-occurring chronic and recurrent diseases. J Clin Epidemiol 1998:51:367-75.

2. Uijen AA, van de Lisdonk EH. Multimorbidity in primary care: prevalence and trend over the last 20 years. Eur J Gen Pract 2008;14(Suppl 1):28-32.

3. Hoffman C, Rice D, Sung HY. Persons with chronic conditions. Their prevalence and costs. JAMA 1996;276:1473-9.

4. Schram MT, Frijters D, van de Lisdonk EH, et al. Setting and registry characteristics affect the prevalence and nature of multimorbidity in the elderly. J Clin Epidemiol 2008;61:1104-12.

5. Koné Pefoyo AJ, Bronskill SE, Gruneir A, et al. The increasing burden and complexity of multimorbidity. BMC Public Health 2015;15:415.

6. Marengoni A, von Strauss E, Rizzuto D, et al. The impact of chronic multimorbidity and disability on functional decline and survival in elderly persons. A community-based, longitudinal study. J Intern Med 2009;265:288-95.

7. Mondor L, Maxwell CJ, Bronskill SE, et al. The relative impact of chronic conditions and multimorbidity on health-related quality of life in Ontario long-stay home care clients. Qual Life Res 2016;25:2619-32.

8. St John PD, Tyas SL, Menec V, et al. Multimorbidity, disability, and mortality in community-dwelling older adults. Can Fam Physician 2014;60:e272-80.

9. Gijsen R, Hoeymans N, Schellevis FG, et al. Causes and consequences of comorbidity: a review. J Clin Epidemiol 2001:54:661-74.

10. Boyd CM, Darer J, Boult C, et al. Clinical practice guidelines and quality of care for older patients with multiple comorbid diseases: implications for pay for performance. JAMA 2005;294:716-24.

11. Caughey GE, Roughead EE, Vitry Al, et al. Comorbidity in the elderly with diabetes: Identification of areas of potential treatment conflicts. Diabetes Res Clin Pract 2010;87:385-93.

12. Wolff JL, Starfield B, Anderson G. Prevalence, expenditures, and complications of multiple chronic conditions in the elderly. Arch Intern Med 2002;162:2269-76.

13. Bähler C, Huber CA, Brüngger B, et al. Multimorbidity, health care utilization and costs in an elderly community-dwelling population: a claims data based observational study. BMC Health Serv Res 2015;15:23.

14. Carstensen J, Andersson D, André M, et al. How does comorbidity influence healthcare costs? A population-based cross-sectional study of depression, back pain and osteoarthritis. BMJ Open 2012;2:e000809.

15. Zulman DM, Pal Chee C, Wagner TH, et al. Multimorbidity and healthcare utilisation among high-cost patients in the US Veterans Affairs Health Care System. BMJ Open 2015;5:e007771.

16. Jones AM, Rice N, dUva TB, et al. Modelling health care costs. Applied Health Economics. 2 ed. Routledge: Oxford, 2013.

17. Kadam UT, Uttley J, Jones PW, et al. Chronic disease multimorbidity transitions across healthcare interfaces and associated costs: a clinical-linkage database study. BMJ Open 2013;3:e003109.

18. Diehr P, Yanez D, Ash A, et al. Methods for analyzing health care utilization and costs. Annu Rev Public Health 1999;20:125-44.

19. Rocca WA, Boyd CM, Grossardt BR, et al. Prevalence of multimorbidity in a geographically defined American population: patterns by age, sex, and race/ethnicity. Mayo Clin Proc 2014;89:1336-49.

20. Ornstein SM, Nietert PJ, Jenkins RG, et al. The prevalence of chronic diseases and multimorbidity in primary care practice: a PPRNet report. J Am Board Fam Med 2013;26:518-24.

21. Canada H. Economic Burden of Illness in Canada. Ottawa: Health Canada, 1998.
22. Austin PC, Daly PA, Tu JV. A multicenter study of the coding accuracy of hospital discharge administrative data for patients admitted to cardiac care units in Ontario. Am Heart $J$ 2002;144:290-6.

23. Gershon AS, Wang C, Guan J, et al. Identifying patients with physician-diagnosed asthma in health administrative databases. Can Respir J 2009;16:183-8.

24. Gershon AS, Wang C, Guan J, et al. Identifying individuals with physcian diagnosed COPD in health administrative databases. COPD 2009;6:388-94.

25. Schultz SE, Rothwell DM, Chen Z, et al. Identifying cases of congestive heart failure from administrative data: a validation study using primary care patient records. Chronic Dis Inj Can 2013;33:160-6

26. Hux JE, Ivis F, Flintoft V, et al. Diabetes in Ontario: determination of prevalence and incidence using a validated administrative data algorithm. Diabetes Care 2002;25:512-6.

27. Guttmann A, Nakhla M, Henderson M, et al. Validation of a health administrative data algorithm for assessing the epidemiology of diabetes in Canadian children. Pediatr Diabetes 2010;11:122-8.

28. Tu K, Campbell NR, Chen ZL, et al. Accuracy of administrative databases in identifying patients with hypertension. Open Med 2007;1:e18-26.

29. Wodchis WP, Bushmeneva K, Nikitovic M, et al. Guidelines on Person-Level Costing Using Administrative Databases in Ontario Health System Performance Research Network (HSPRN). 2013.

30. Ontario Ministry of Health and Long Term Care. Schedule of benefits for physician services: consultations and visits. 2014 http://www. health.gov.on.ca/english/providers/program/ohip/sob/physserv/a consul.pdf.

31. Canadian Institute for Health Information. CCRS Technical Document-Ontario RUG Weighted Patient Day. Ottawa: Canadian Institute for Health Information;, 2014

32. Matheson FI, Dunn JR, Smith KL, et al. Development of the Canadian Marginalization Index: a new tool for the study of inequality. Can $J$ Public Health 2012;103(8 Suppl 2):S12-16.

33. Matheson FI, White HL, Moineddin R, et al. Neighbourhood chronic stress and gender inequalities in hypertension among Canadian adults: a multilevel analysis. J Epidemiol Community Health 2010;64:705-13.

34. Nagl A, Witte J, Hodek JM, et al. Relationship between multimorbidity and direct healthcare costs in an advanced elderly population. Results of the PRISCUS trial. Z Gerontol Geriatr 2012;45:146-54.

35. Vogeli C, Shields AE, Lee TA, et al. Multiple chronic conditions: prevalence, health consequences, and implications for quality, care management, and costs. J Gen Intern Med 2007;22(Suppl 3):391-5.

36. Kralj B. Measuring Rurality - RIO2008 BASIC:Methodology and Results 2008. https://www.oma.org/Resources/Documents/ 2008RIO-FullTechnicalPaper.pdf.

37. Manning WG, Mullahy J. Estimating log models: to transform or not to transform? J Health Econ 2001;20:461-94.

38. Yoon J, Zulman D, Scott JY, et al. Costs associated with multimorbidity among VA patients. Med Care 2014;52:S31-S36.

39. Guthrie B, Saultz JW, Freeman GK, et al. Continuity of care matters. BMJ 2008;337:a867.

40. Kerr EA, Heisler M, Krein SL, et al. Beyond comorbidity counts: how do comorbidity type and severity influence diabetes patients' treatment priorities and self-management? J Gen Intern Med 2007;22:1635-40.

41. Macintyre S, Hunt K, Sweeting H. Gender differences in health: are things really as simple as they seem? Soc Sci Med 1996;42:617-24.

42. Rizza A, Kaplan V, Senn O, et al. Age- and gender-related prevalence of multimorbidity in primary care: the Swiss FIRE project. BMC Fam Pract 2012;13:113.

43. Abad-Díez JM, Calderón-Larrañaga A, Poncel-Falcó A, et al. Age and gender differences in the prevalence and patterns of multimorbidity in the older population. BMC Geriatr 2014;14:75

44. Orueta JF, Nuño-Solinís R, García-Alvarez A, et al. Prevalence of multimorbidity according to the deprivation level among the elderly in the Basque Country. BMC Public Health 2013;13:918.

45. Williamson DL, Stewart MJ, Hayward K, et al. Low-income Canadians' experiences with health-related services: implications for health care reform. Health Policy 2006;76:106-21.

46. Crawford SM, Sauerzapf V, Haynes R, et al. Social and geographical factors affecting access to treatment of colorectal cancer: a cancer registry study. BMJ Open 2012;2:e000410.

47. Wodchis WP, Austin PC, Henry DA. A 3-year study of high-cost users of health care. CMAJ 2016;188:182-8. 
48. Canadian Institute for Health Information. Prescribed Drug Spending in Canada, 2013: A Focus on Public Drug Programs. Ottawa: Canadian Institute for Health Information, 2014.

49. Stewart M, Fortin M, Britt HC, et al. Comparisons of multimorbidity in family practice--issues and biases. Fam Pract 2013;30:473-80.

50. Diederichs C, Berger K, Bartels DB. The measurement of multiple chronic diseases--a systematic review on existing multimorbidity indices. J Gerontol A Biol Sci Med Sci 2011;66:301-11.
51. Le Reste JY, Nabbe P, Manceau B, et al. The European General Practice Research Network presents a comprehensive definition of multimorbidity in family medicine and long term care, following a systematic review of relevant literature. J Am Med Dir Assoc 2013;14:319-25.

52. Islam MM, Yen L, Valderas JM, et al. Out-of-pocket expenditure by Australian seniors with chronic disease: the effect of specific diseases and morbidity clusters. BMC Public Health 2014;14:1008. 